Journal of Environmental Science and Public Health

doi: $10.26502 /$ jesph. 96120044

Volume 3, Issue 1

Research Article

\title{
Prevalent Diseases among Inmates in Three Federal Prisons in South-East Geopolitical Zone of Nigeria: A Peep into the Environmental Factors
}

\author{
Otuu Fred $\mathbf{C}^{1 *}$, Shu Elvis $\mathbf{N}^{2}$ \\ ${ }^{1}$ Department of Pharmaceutics, University of Nigeria, Nsukka, Nigeria \\ ${ }^{2}$ Department of Pharmacology and Therapeutics, University of Nigeria, Enugu Campus, Nigeria
}

"Corresponding Author: Otuu Fred C, Department of Pharmaceutics, University of Nigeria, Nsukka, Nigeria, Email: fred.otuu@unn.edu.ng

Received: 27 November 2018; Accepted: 14 December 2018; Published: 07 January 2019

\begin{abstract}
Introduction: This study analyzed the prevalent diseases among the inmates of three federal prisons in South-East geo-political zone of Nigeria.

Methodology: Well structured questionnaires designed to reflect demography, prevalent diseases and environmental problems were administered to the interested participants who gave verbal consent to the voluntary, first person informed consent form which was read in the language of the inmates (English or Igbo, Yoruba, Hausa languages) by a nurse, as they were not permitted to write.
\end{abstract}

Result: The prisons were dominated by male prisoners, 92.5\%, 85.0\%, 87.2\%, in Abakaliki, Enugu and Onitsha prisons respectively. The age brackets $21-30 \mathrm{yrs},(42.3 \%, 43.9 \%)$ and $31-40 \mathrm{yrs}(26.7 \%, 25.0 \%)$, were predominant age in Abakaliki and Onitsha prisons respectively. Enugu prison inmates did not indicate their ages. Enugu prison had more number of literates with tertiary education (45.3\%), followed by Abakaliki prison (30.9\%) and Onitsha prison $(12.2 \%)$. In general, there were uneven distributions of the inmates into sex $\left(\chi^{2}=127.1, \mathrm{p}<0.0001\right)$, educational level $\left(\chi^{2}=108.5, \mathrm{p}<0.0001\right)$ and length of time spent in the different prisons $\left(\chi^{2}=100.4, \mathrm{p}<0.0001\right)$ in the three prisons. The most prevalent disease was malaria $(81.06 \%, 77.67 \%$ and $73.33 \%)$, followed by cough and 
catarrh $(63.79 \%, 68.67 \%, 60.0 \%)$, rashes $(58.77 \%, 59.27 \%, 58.97 \%)$ in Abakaliki, Enugu and Onitsha respectively. Among the environmental problems reported were overcrowding $(76.60 \%, 70.0 \%, 60.51 \%)$, poor toilet facility $(72.98 \%, 48.33 \%, 50.77 \%)$, lack of portable water $(64.35 \%, 44.0 \%, 43.08 \%)$.

Interpretation: Abakaliki prison showed highest incidence of disease burdens, probably as result of poor structural facilities.

Keywords: Demography; Prevalent Diseases; Environmental factors; Relative Humidity; Inmates

\section{Introduction}

The Nigerian prison services have evolved through many stages. Following the declaration of Lagos as a colony in 1861 the Western-type prison was established in Lagos with the formation of a police force of about 25 constables to administer the colonial policy. Subsequently the Broad street prison was established in 1872, with initial capacity of 300 inmates. As the British interest progressed into the hinterland and British protectorate was established, the establishment of prisons outside the Lagos colony became inevitable. Thus by 1910, there already were prisons in Degema, Calabar, Onitsha, Benin, Ibadan, Sapele, Jebba and Lokoja. The abolition of Native Authority prisons in 1968 and the subsequent unification of the Prisons Service in Nigeria therefore marked the beginning of Nigerian Prisons Service as a composite reality. Prior to this, the prisons in the North were under the general supervision of the Northern Inspector General of Police who was ex-officio Director of Prisons. In the same vain the Director of Prisons was in charge of the prisons in the south. The Gobir report put an end to all that. As a consequence of that report Native Authority prisons were abolished with effect from $1^{\text {st }}$ April, 1968. However, due to the vagaries of the civil war then raging in the country, it was not until 1971 that the government white paper on the reorganization of the prisons was released. It was followed in 1972 by Decree No.9 of 1972 which spelt out the goals and orientation of the Nigerian Prisons Service. The Prisons was charged with taking custody of those legally detained, identifying causes of their behavior and retraining them to become useful citizens in the society.

There have been massive transformations in the Service since 1972. It has undergone some reorganization from its modest three Directorates in 1980 to six Directorates in 1993. There was the 1986 reorganization of the Prisons consequent upon the creation of the Customs, Immigrations and Prisons Board and centralization of the administrations of these paramilitary Services in the Board. There was also the removal of the Services from the Civil Services in 1992. It now has command structure that boasts of 8 zonal commands, 36 State commands, 1 FCT Command, 155 Prisons including farm centers and 83 Satellite Prisons. It also has four Training Schools, one Staff College and 3 Borstal Institutions. In the last ten years no less than 12 new satellite prisons and 3 prison hospitals have been built. These efforts, though aimed at improving the general conditions of the prisons, have not addressed some critical areas. The general health and environment of the prison inmates are yet to be improved. Different diseases abound and some seem to be more peculiar to prison environment with effects that some prison inmates 
become more diseased on their discharge than they were before incarceration. Prison welfare should be holistic, cutting across structural modification, feeding improvement, social reorientation and environmental healthiness.

Several studies have implicated the prison environments in diseases among prison inmates, [1-4]. In their study on the assessment of a five-year disease profile of inmates in three prison formations in Kaduna State, Audu et al. [3] reported psychiatric cases $(24.1 \%)$ as the dominant health problem, followed by gastro-intestinal disease $(22.6 \%)$, respiratory tract disease $(10.1 \%)$, dermatology/allergy (5.4\%), cardiovascular diseases (2.4\%). Among the specific conditions examined, malaria (21.6\%), was most prevalent, followed by accident/deliberate harms (0.6\%), tumors $(0.6 \%)$, TB $(0.2 \%)$ and HIV (0.1\%). Elekwechi et al. [1], reported that lack of portable water, inadequate sewage facilities and severe overcrowding have resulted in dangerous and unsanitary conditions in Nigerian prisons. These conditions are associated with in-breeding of communicable diseases. The study also implicated poor environment as a causative factor in the prevalence of mono-ocular and bilateral blindness. Poor toilet facilities, lack of or inadequate provision of recreational facilities, poor ventilation, and domestic wastes, effluent discharges from toilet system and attitude of the Warders to the inmates are among the environmental components that may affect the general health of the prison inmates. Research so far has bordered on improvement of physical structures to enhance better accommodation facilities in the prisons and welfare to improve the feeding standards of the inmates [5]. Not much has been reported on the general environmental and health status of the prisons in Nigeria. Realizing the relationship between a good environment and good health, it becomes necessary that the effects of environmental components of the prison facilities be studied, to identify the relationship between the environmental status of the prison formation and prevalent diseases among the prison inmates. Presently, no such study has been reported. This formed the basis for this study.

\section{Methodology}

\subsection{Protocol for the study}

The protocol for the study was reviewed by the Ethics Review Committees of the College of Medicine, University of Nigeria Nsukka. Peaceful community entry into the prison environments was ensured by obtaining authorization letter from the Office of the Assistant Controller General of Prisons, Zone 'G', Benin City, Edo State, Nigeria and subsequently from the Controller of prison, State Headquarter, Enugu state. The voluntary, first person Informed Consent of the inmates involved in the study was then obtained. The nurse explained to each inmate the research project: aim and objectives, funding, methods, the involvement of the inmates and the length of time of involvement, discomforts or risks, benefits, usefulness of the research, and plans for the use of the research findings. This information was in the Informed Consent Form, which was read in the language of the inmates (English or Igbo, Yoruba, Hausa languages).The inmates gave verbal consent because they were not allowed to write.

\subsection{Description of the study area}

The study was carried out in three Federal Prisons in Enugu, Abakaliki, and Onitsha in Enugu, Ebonyi and Anambra states, respectively. 
Enugu prison, a maximum prison was built about one hundred and two (102) years back, and is one of the oldest prisons in Nigeria. Enugu is the administrative capital of Enugu State, South-Eastern Nigeria. It has the population of 722,000 [6], and density estimate of $6,400 / \mathrm{km}^{2}$. It is located between $6^{\circ} 21^{\prime} \mathrm{N}$ and $6^{\circ} 30^{\prime} \mathrm{N}$ and $7^{\circ} 26^{\prime} \mathrm{E}$ and $7^{\circ}$ 30E. It has a tropical humid climate. Mean annual rainfall ranges from $1600 \mathrm{~mm}$ and 2,500 $\mathrm{mm}$ with three to four months of dry season, the dried month having $29 \mathrm{~mm}$ of rainfall. Mean monthly temperature ranges between $27^{\circ} \mathrm{C}$ and $29^{\circ} \mathrm{C}$. The prison is located at the heart of Enugu metropolis opposite the Enugu (Ogboete) main market, and was originally designed to house 638 inmates. At the time of the study, February-May 2017, the prison housed 1995 inmates, comprising of 1938 males and 57 females.

Abakaliki prison is a medium security prison built by the colonial masters in 1946 to hold a maximum of 387 inmates. Located at the heart of Abakaliki- the capital city of Ebonyi State, it has a geo-position between latitudes $6^{\circ} 08^{1} \mathrm{~N}$ and $6^{\circ} 24^{1} \mathrm{~N}$ and longitudes $8^{\circ} 00^{1} \mathrm{E}$. The prison is a short distance away from the Government House, the State Police Headquarter and the Federal Teaching Hospital, and is considered the worst prison in south east geopolitical zone in terms of structure with a large part of the structure being built with mud which creates breeding ground for many disease pathogens. At the time of the study the prison housed over 1000 inmates. Onitsha Federal prison is one of the oldest prisons in Nigeria, having been in existence before 1910 alongside such other prisons as Degema, Calabar, Benin, Ibadan, Sapele, Jeba and Lokoja. The prison is located at the heart of Onitsha city-the most commercial city in Anambra State. Onitsha is a city located on the eastern bank of the Niger River. A metropolitan city, it is known for its river port and as an economic hub for commerce, industry, and education. It hosts the Onitsha Main Market, the largest market in Africa in terms of geographical size and volume of goods. In the 2006 Nigerian census, Onitsha had an estimated city proper population of over quarter a million people, and, as of 2016, had an estimated urban population of 7,425,000 [7]. The prison originally designed to house 326 inmates now holds over a thousand inmates.

\subsection{Sampling and data acquisition}

Research Assistants comprising of selected prison staff of three nurses (two females, one male) and three other staff members in the social welfare unit were recruited for the exercise. Well structured questionnaires designed to reflect demography, prevalent diseases, the environmental problems and suggested improvement were administered to the inmates. The Research Assistants were given structured training that enabled them to obtain appropriate responses from the participants. The response was hundred percent successful. The study lasted for four months, from February $15^{\text {th }}$ to June $15^{\text {th }} 2017$.

\section{Results}

The result of the study is presented in table 1 and Figures 1-3. Table 1 represents the demographic features of the inmates in the three prisons, out of 359 respondents in Abakaliki, 332 (92.5\%) were males and 24 (7.5\%) were females. In Enugu prison 300 inmates responded to the questions, out of which 255 (85.0\%) were males, 25 (8.3\%) were females, and 20 (6.7) did not indicate their sexes. In Onitsha prison, 195 inmates were sampled, out of which 
$171(87.2 \%)$ were males, and $25(12.8 \%)$ were females. The age range of the inmates in the three prisons was between 18 and above 50 years. In Abakaliki prison, the inmates in age range between 18-20 years were 5 (1.4\%), 21-30 years were 152 (42.3\%), 31-40 years were 96 (26.7\%), and 41-50 years were 56 (15.6\%), while those above 50 years were $13(3.6 \%)$ and $37(10.31 \%)$ did not indicate their ages. The inmates in Enugu prison did not indicate their ages. In Onitsha prison, those within the age bracket of 18-20 years were 37 (18.9\%), 21-30 years were 86 (43.9\%), 31-40 years, were 49 (25.0\%), 41-50 years were $18(9.2 \%)$, while those above 50 years of age were 5 $(2.6 \%)$. One person, $1(0.5 \%)$, did not indicate age.

A total number of inmates with primary education in Abakaliki were 55 (15.2\%), in Enugu 47 (15.7\%), in Onitsha 45 (22.9\%). In Abakaliki, Enugu and Onitsha prisons, 188 (52.4\%), 114 (38.0\%), 126 (64.3\%) respectively had secondary education. While Abakaliki prison had 111 (30.9\%) inmates with tertiary education, Enugu and Onitsha had 136 (45.3\%), 24 (12.2\%), respectively. In Abakaliki prison, 5 (1.4\%) inmates did not indicate their level of education, while $3(1.0 \%), 1(0.5 \%)$ in Enugu and Onitsha respectively did not indicate their educational level. The length of period in the prisons ranged from less than 2 years to above 10 years. In Abakaliki, the inmates who had spent less than 2 years were 192 (53.5\%), while in Enugu they were 78 (26.0\%) and Onitsha had 101 (51.5\%). Those who had spent 2-5 years in Abakaliki were 107 (29.8\%), 110 (36.7\%) in Enugu, and 68 (34.7\%) in Onitsha. The inmates who had spent 6-9 years in Abakaliki were 24 (6.7\%), in Enugu 76 (25.3\%), and in Onitsha 19 (9.7\%). The inmates who had spent 10 years and above in Abakaliki were 19 (5.3\%), in Enugu 6 (2.0\%) and Onitsha 5 (2.6\%). In Abakaliki 17 (4.7\%) did not indicate the length of time spent in prison, while in Enugu and Onitsha 30 $(10.0 \%), 3(1.5 \%)$ respectively, did not indicate the period spent in the prison.

In general, there were uneven distributions of the inmates into sex $\left(\chi^{2}=127.1, p<0.0001\right)$, educational level $\left(\chi^{2}=108.5, p<0.0001\right)$ and length of time spent in the different prisons $\left(\chi^{2}=100.4, p<0.0001\right)$ in the three prisons.

\begin{tabular}{|l|l|l|l|l|}
\hline S/N & Demography & Abakaliki n (\%) & Enugu n (\%) & Onitsha n (\%) \\
\hline 1 & Sex & & & \\
& Male & $332(92.5)$ & $255(85.0)$ & $171(87.2)$ \\
& Female & $27(7.5)$ & $25(8.3)$ & $25(12.8)$ \\
& Not indicated & $0(0.0)$ & $20(6.7)$ & $0(0.0)$ \\
\hline 2 & Age & & & \\
& $18-20$ & $5(1.4)$ & Nil & $37(18.9)$ \\
& $21-30$ & $152(42.3)$ & Nil & $86(43.9)$ \\
& $31-40$ & $96(26.7)$ & Nil & $49(25.0)$ \\
& $41-50$ & $56(15.6)$ & Nil & $18(9.2)$ \\
& $51-$-above & $13(3.6)$ & Nil & $1(2.6)$ \\
& Not indicated & Nil & Nil & $1(0.5)$ \\
\hline 3 & Educational Level & & & \\
\hline
\end{tabular}




\begin{tabular}{|l|l|l|l|l|}
\hline & Primary School & $55(15.2)$ & $47(15.7)$ & $45(22.9)$ \\
& Secondary School & $188(52.4)$ & $114(38.0)$ & $126(64.3)$ \\
& Tertiary School & $111(30.9)$ & $136(45.3)$ & $24(12.2)$ \\
& Not indicated & $5(1.4)$ & $3(1.0)$ & $1(0.5)$ \\
\hline 4 & Length of time spent in the prison & & & \\
& Less than 2yrs & $192(53.5)$ & $78(26.0)$ & $101(51.5)$ \\
& $2-5 y r s$ & $107(29.8)$ & $110(36.7)$ & $68(34.7)$ \\
& 6-9yrs & $24(6.7)$ & $76(25.3)$ & $19(9.7)$ \\
& $10 y r s$ and above & $19(5.3)$ & $6(2.0)$ & $3(2.6)$ \\
& Not indicated & $17(4.7)$ & $30(10.0)$ & $3(1.5)$ \\
\hline
\end{tabular}

Table 1: Demography of the Prison Inmates.

Figure 1, represents the prevalent diseases among the inmates in the three prisons. In the three prisons, malaria was the most prevalent disease 291 (81.06\%), 233 (77.67\%), 143 (73.33\%), followed by cough and catarrh, 229 (63.79\%), 206 (68.67\%) and 117 (60.0\%), rashes, 211 (58.77\%), $179(59.27 \%)$ and 115 (58.97\%), chest pain, 179 (49.86\%), 134 (44.67\%), 95 (48.72\%), eye problem, 175 (48.75\%), 91 (30.33\%), 80 (41.03\%) constant headache, 169 (47.08\%), 92 (30.67\%), 77 (39.49\%) diarrhea, 154 (42.90\%), 131 (43.67\%), 73 (37.44\%), hypertension, 148 (41.23\%), 47 (15.67\%), 39 (20.00\%) sore throat/tonsillitis, 102 (28.41\%, 110 (36.67\%), 37 (18.97\%) respectively. There were significant differences $(\mathrm{P}<0.05)$ among the prisons in sore throat/tonsillitis, constant headache, constipation, ringworm/hair loss, hypertension/high blood pressure, tuberculosis and eye problems.

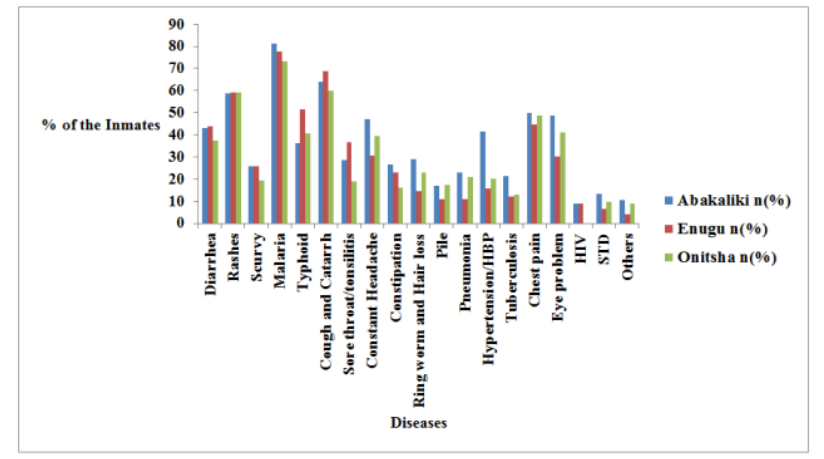

Figure 1: Prevalent Diseases among the inmates in the three Prisons.

Figure 2, represents time spent in the prisons and the diseases prevalence. The responses to the questionnaire indicated that the period with the highest diseases prevalence was less than two years, with malaria been the most prevalent disease, followed by cough and catarrh, rashes, chest pain, eye problem, constant headache in that order. The period 2-5yrs also witnessed the same pattern of diseases prevalence, with the period greater than 9yrs, recording the least diseases prevalence. 


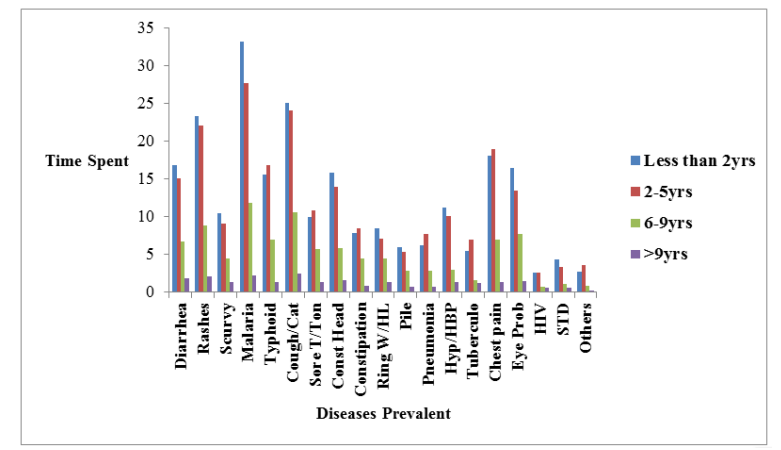

Figure 2: Diseases Prevalence against Time Spent in the three Prisons.

Figure 3, represents environmental problems confronting the inmates within the three prisons. In the three prisons, the inmates strongly agreed that overcrowding 275 (76.60\%), $210(70.0 \%), 118(60.51 \%)$, was the most prevalent environmental problem, followed by poor toilet facilities, 262 (72.98\%), 145 (48.33\%), 99 (50.77\%), lack of Medicare, 234 (27.5\%), 151 (17.7\%), 89 (10.4\%), poor ventilation 232 (27.1\%), 161 (18.8\%), 76 (8.9\%), lack of portable water, 231 (64.35\%), 132 (44.0\%), 84 (43.08\%, inadequate water facilities 215 (25.2\%), 135 (15.8\%), 79 (9.3\%), lack of exercise, 205 (57.10\%), 119 (39.67\%), 106 (54.36\%), and dirty environment, 180 (50.14\%), 101 $(33.66 \%), 81(41.54 \%)$. There were significant differences $(\mathrm{P}<0.05)$ among the prisons in all the environmental problems.

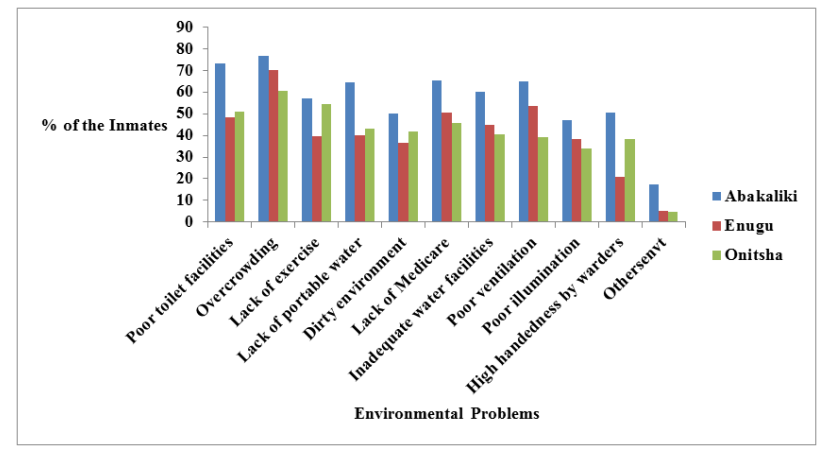

Figure 3: The Inmates that Strongly Agreed to Environmental Problems in the three Prisons.

\section{Discussion}

This study compared the prevalence of some diseases among the inmates of three federal prisons in South-East geopolitical zone in Nigeria, implicating different environmental conditions of the prisons as possible causes. The prisons were dominated by male prisoners, with the age brackets 21-30 yrs and 31-40 yrs, being the predominant in Abakaliki and Onitsha prisons. These age brackets represent the most productive periods of human life, characterized by hyper-activity and high sense of belonging. When individuals within these age brackets are imprisoned, their psycho-social values are compromised with the effects that depression and anxiety may be developed. Depressive disorders have been reported as a leading cause of burden in Global Burden of Diseases [8]. 
There are documented evidences of the relationship between depression and ischemic heart diseases, high blood pressure, obesity, diarrhea and chest pain $[9,10]$.

Enugu prison had more number of literates with tertiary education than Onitsha prison. This could be attributed to the location of the prison in Enugu metropolis which is known to have over four tertiary institutions. Recently, an inmate of Enugu prison was reported to have emerged the best post-graduate student of National Open University of Nigeria, nationwide, and most of the tertiary educated inmates are from these schools. In Onitsha, the nearest tertiary institutions are all outside Onitsha metropolis where the prison is located. The proximity of the prison to higher institutions and other public institutions may be contributive to educational status of the inmates, especially, in this era of Open University where inmates are allowed to attend classes within selected areas, under security watch. There is a renewed interest in the role of social institutions in the onset of crime. In their work, Steven et al. opined that social institutions influence how social life is regulated and facilitate the functioning of social system. Thus, prisons in the vicinity of tertiary institutions harbor inmates within the school age bracket.

Educational status significantly influences coping with the challenges of incarceration among prison inmates, favouring those with lower level of education. This may be explained by the fact that the less educated ones have lesser prospects than the more educated individuals. A person with fewer prospects in life is most likely to feel less pain with his/her situation and therefore cope better. On the other hand the more educated people feel greater sense of loss and pain due to their incarceration [4]. These feelings will limit their effectiveness in coping with the challenges of incarceration, resulting in the development of stress-related diseases such as high blood pressure, irritable bowel movement, and eye problems. It is a medical fact that stress and anxiety attenuate immune capacity $[11,12]$. Diseases onset and progression are dependent upon the immune capacity of an individual [13, 14]. The underlying denominator in most disease pathology and pathogenesis is alteration of normal biochemical mechanisms beyond the normal resilient properties involved in delicate dynamic haemostatic equilibrium. Few biochemical compounds are as responsive as hormones to adverse environmental conditions on human health, and among hormones of interest are the corticosteroids, especially, cortisol. Cortisol is a corticosteroid or glucocorticoid produced by the adrenal cortex. It is usually referred to as the "stress hormone" as it is involved in response to stress and anxiety. It increases blood pressure and blood sugar, and reduces immune responses and is implicated in patients with conditions such as reduced stress tolerance, fatigue, sleep disorders, depression and persistent high blood pressure increase.

The periods of stay in the prisons vary. Greater number of the inmates had spent less than $2 \mathrm{yrs}$ in all the prisons, followed by $2-5 y r s$. Demography is implicated in the spread of environmental born diseases $[15,16]$.There was periodic influence in the prevalence of the diseases, especially, malaria disease among the inmates. The inmates who had spent lesser periods in the prison suffered more disease burdens. This could be explained from the stand point of naturally acquired immunity to falciparum malaria which seems to have time and exposure dependent effects [17].Thus resistance to malaria disease improved as the period of stay in the prison increased. 
The prevalent diseases were malaria, cough and catarrh, rashes, chest pain, eye problem, diarrhea, constant headache, hypertension, sore throat/tonsillitis in this order, in all the three prisons. This finding agrees with that of Audu, et al [3]. Abakaliki prison recorded the highest incidences of malaria, constant headache, constipation, ring worm and hair loss, pneumonia, hypertension, tuberculosis, chest pain, eye problem, and STD. Enugu recorded the highest incidences of diarrhea, rashes, typhoid, cough and catarrh, sore throat/tonsillitis. Onitsha prison recorded the least incidences in all the diseases. Malaria is an environmental vector-born disease which breeds favorably in dirty environment [18].

Abakaliki recorded more disease burdens than the other two prisons. Abakaliki prison is the only prison among the three prisons with mud houses. These would not only provide crevices on the walls for mosquito breeding and proliferation of other vectors of public health interest, but will also be more relatively humid than the other two. Relative humidity of indoor environments has both direct and indirect effects on health and comfort. Direct effects refer to effects on physiological and biochemical processes, such as the physiology and biochemistry of blood pressure regulation, circadian rhythm, and indirect effects in turn refer to effects that result from the impact of humidity on pathogenic organisms or chemicals. Epidemiological studies suggest that relative humidity can indirectly affect the incidence of allergies and infectious respiratory diseases. This is related to the survival and probability of effective contact of infectious or allergenic organisms, such as fungi, mites, bacteria, and viruses. Relative humidity also affects the concentration of chemicals in the air, as it affects their off gassing from building materials and disinfectant by-products. Several studies have shown that relative humidity for minimizing the adverse indirect health effects lies within 40-60\%. Indoor air humidity, in terms of perceived dry air (dryness) and potentially associated health effects is an important parameter (relative humidity (RH) or absolute humidity (AH) both in the private and public environment. There is an increasing recognition of the impact of humidity on virus survival and transmission and sleep quality, regarding derivation of a safe limit for indoor air humidity. The relative higher incidence of high blood pressure/hypertension in Abakaliki prison may not be unrelated with the relative low comfort, such as poor sleep quality, associated with indoor high humidity.

The high incidences of ring worm and hair loss, pneumonia, tuberculosis, chest pain, and eye problem in Abakaliki prison may also be attributed to the structural facilities and the possible higher indoor relative humidity. These diseases are associated with fungal and bacterial organisms that thrive well in tropical humid environment. Some of the fungi particles associated with the diseases above include Fusarium solani, Rhizopus spp, spp, Absidia spp,Trichophyton mentagrophytes var interdigitale (Human strain), which are dermatophytes with global as well as cosmopolitan distribution and are associated with dirty indoor environments. They have been linked with skin and eye diseases, [19-21]. F. solani, for example, has been implicated in such diseases as osteomyelitis, skin infection, fungemia, and endophthalmitis. In immune-compromised patients, $F$. solani is one of the most common agents in disseminated and cutaneous infections and has been reported as a major cause of fungal keratitis in HIV positive patients in Africa [20]. 
High relative humidity will encourage the existence of cisterns, puddles and low air current which are reported to favor mosquito breeding. In their study on the impact of small variations in temperature and humidity on the reproductive activity and survival of Aedes aegypti (Diptera, Culicidae) on Ethiene, Arruda Pedrosa de Almeida et al. observed that the greater concentration of $A$. aegypti in warm, rainy seasons is strongly influenced by the effects of temperature and humidity on several aspects of the mosquito lifecycle. The rise in population density favors the occurrence of epidemics in warm, rainy seasons, decreasing in drier periods, when the number of females in the environment is reduced. Yamana, et al. [22] demonstrated that relative humidity can play a significant role in mosquito population and malaria transmission dynamics. Damped mud walls in a humid tropical environment will encourage the ceding of fungal spores and proliferation of aquatic algae which are reported to favour mosquito breeding [23, 24].

Malaria is a contagious disease easily spread in a crowded environment. Ehonwa included malaria diseases among contagious diseases still thriving in Nigeria prisons as a result of overcrowding and unhygienic environment. The high incidence of malaria disease in Abakaliki prison could be explained by the relatively poor environment as seen in the physical structure within the prison environment. The National Human Rights Commission (NHRC), visited the Abakaliki prison, in 2016 and observed, that the security fence was the only building with cement or modern materials. Other environmental components such as the septic tanks and soak-away pits were in states of disrepair, resulting in the effusion of organic wastes into the environment. One of the major consequences of organic and faecal decomposition is the generation of Green House Gases (GHGs) such as hydrogen sulphide, oxides of carbon and methane [25], especially when the concrete slabs covering the septic tanks and soak-away are dilapidated with cracks and openings giving way to effluent discharges. GHGs are associated with micro-climatic alteration, including rise in temperature. Mosquito is a temperate organism which breeds more in a relatively high temperature environment. Therefore, the environment of Abakaliki prison was responsible for high prevalent of malaria disease. Other prevalent diseases in Abakaliki are also associated with the environment.

Poor toilet facility, overcrowding and dirty environment were reported as the most prevalent environmental factors in Abakaliki prison, more than in the other two prisons. This correlates with the more incidences of malaria diseases in Abakaliki. This is in agreement with the reports of Ehonwa 1996. Transmission of malaria parasite from one person to the other is favored by overcrowding. Cough and catarrh as well as rashes are environmental borne diseases that are favored by poor environmental hygiene. Cough is a respiratory tract disease caused by viral and bacterial pathogens that are air-born.

A review of the health effects of relative humidity in indoor environments suggests that relative humidity can affect the incidence of respiratory infections and allergies. Experimental studies on airborne-transmitted infectious bacteria and viruses have shown that the survival or infectivity of these organisms is minimized by exposure to relative humidity between 40 and $70 \%$. The indoor size of allergenic mite and fungal populations is directly dependent upon the relative humidity. Mite populations are minimized when the relative humidity is below $50 \%$ and reach a maximum size at $80 \%$ relative humidity. Most species of fungi cannot grow unless the relative humidity exceeds 
$60 \%$. Relative humidity also affects the rate of off gassing of formaldehyde from indoor building materials, the rate of formation of acids and salts from sulfur and nitrogen dioxide, and the rate of formation of ozone [26]. The influence of relative humidity on the abundance of allergens, pathogens, and noxious chemicals, especially the hydrophilic ones [27] suggests that indoor relative humidity levels should be considered as a factor of indoor air quality with potentials for adverse health effects on humans.

Enugu recorded the highest incidences of diarrhea, rashes, typhoid, cough and catarrh, sore throat/tonsillitis. The Enugu prison is located very close to the Enugu main market motor park with high presence of vehicular activities. The infiltration of tail-pipe ambient air pollutants into the prison cells and affecting the cells indoor-air quality (IAQ) is strongly possible. IAQ can be affected by various chemicals, including gases (i.e., carbon [11] oxide, ozone, Ammonia, Hydrogen sulphide,), volatile organic compounds (VOCs), particulate matter (PM) and fibers, organic and inorganic contaminants, and biological particles such as bacteria, fungi, and pollen. The large number of variables that impact IAQ inevitably leads to a wide range of studies and scientific papers published in journals from many kinds of scientific subjects (e.g. chemistry, medicine, environmental sciences, etc.). Impact of gaseous profile on the health of prison inmates has been studied in some prison facilities in developed countries, associating some of the diseases as observed in Enugu prison formation with poor IAQ.

Otuu et al. [28] associated vehicular activities with incidence of high carbon [29] oxide emission at Osioma, Aba in Abia state, posing potential health challenges to the artisans whose daily duties expose them to the vehicular tailpipe emission. Sources and effects of carbon [29] oxide on prison health have been studied in prisons in many developed countries. Constant dull headache, blurred vision (eye problems), nausea or vomiting (stomach problems), weakness are among the many diseases associated with constant exposure to carbon [29] oxide emission. Location of Enugu prison to the relatively high anthropogenic influential site may be responsible to some of the diseases more prevalent in Enugu prison. In a culture characterized by inadequate public health awareness, poor diagnostic facilities and ineffective national health policy, the possibility of deaths resulting from undiagnosed $\mathrm{CO}$ poisoning may not be ruled out.

Other gases such as sulphur oxides, ammonia, methane, nitrous oxides are also associated with public health problems. The close proximity of toilet facilities in the prison cells to the living spaces of the inmates expose them to the dangers of these gases, most of which are generated when fecal and other human wastes are decomposed [25].

Onitsha prison recorded the least diseases burdens than the other two prisons studied. Located at a relatively more serene low cost housing environment in Onitsha, the prison enjoys better environmental quality than the other two prisons. The environmental friendly developments, such as the construction of Relaxation Park within the prison and the latest establishment of skill acquisition center, both by the catholic institution, may have a profound positive influence on the lower diseases burdens among the inmates. The ornamental plants decorating the park are of health benefit to the inmates as they provide shades and comfort zones within the prison environment. In recent times, plants have been recognized as remediation agents in polluted environment because of their pollutant sinking 
properties [29, 30]. Consequently, plants generally, especially the ornamental plants are now cultivated for their phyto-remediation potentials against anthropogenic-induced pollution [28].

\section{Conclusion and Recommendations}

This study agrees with several other studies which implicated the prison environments in diseases among prison inmates, [1-4] on the broad perspective. The Abakiliki prison recorded more disease burdens probably because of its structural poverty which potentiates diseases pathology and pathogenesis. The Enugu prison has disease burdens that may be related to its location as the possibility of infiltration of tail-pipe emission contaminants into the prison environment is not in doubt.

Much as our study and those of other studies have been done on the environmental relationship of prison diseases, there is yet a need to identify specific components and factors of the environment, isolate them and critically examine the different ways they may be contributive to the prevalence of some diseases in the prison formations. Such environmental components as the physical structure, items of furniture (Fomites) and factors as relative humidity, ambient air temperature, indoor air quality (microclimatic), out-door gaseous profile and environmental metallation are known to be relevant in the overall health status of an individual. Understanding their roles in the epidemiology of some diseases among the prison inmates will be beneficial in the holistic management of prison health. This study is a prelude to series of our studies on the environmental and biochemical basis of prevalent diseases in some prisons in the South east geopolitical zone of Nigeria.

\section{References}

1. Lekwachi EE, Ezegwui I, Ezepue U, et al. Pattern of Eye Disorders Among Inmates of Nigerian Prisons. Orient Jour of Medicine Journal House 21 (2009): 1-4.

2. Opafunso ZO, Adepoju OO. Prison Reforms System and Inmate's Welfare in Nigeria. Arts Social Sci J 7 (2016): 166 .

3. Audu O, Akorede KW, Joshua IA. Five Year Review of Disease Profile of Inmates in Three Prison Formations in Kaduna State, Nigeria: A case study. Nigerian Hospital Practice, Journal House 13 (2014): $5-6$.

4. Chikwe Agbakwuru, Emi Maria Ibe-Godfrey. Correlates of coping with the challenges of incarceration among Nigerian prison inmates. British Journal of Education 5 (2017): 69-77.

5. Asokhia MO, Osumah Obaze Agbonluae. Assessment of Rehabilitation Services in Nigerian Prisons in Edo State. American International Journal of Contemporary Research 3 (2013): 224-230.

6. Federal Republic of Nigeria Official Gazette. SI No. 1: Legal Notice on Publication of 2006 Census Final Result 96 (2006).

7. Demographia. Demographia World Urban Areas (2016).

8. Alize J Ferrari, Fiona J Charlson, Rosana E Norman, et al. Burden of Depressive Disorders by Country, Sex, Age, and Year: Findings from the Global Burden of Disease Study 2010. PLoS Med 10 (2013): 1-12. 
9. Rozanski A, Blumenthal JA, Kaplan J. Impact of psychological factors on the pathogenesis of cardiovascular disease and implications for therapy. Circulation 99 (1999): 2192-2217.

10. Lett HS, Blumenthal JA, Babyak MA, et al. Depression as a Risk Factor foR Coronary Artery Disease: Evidence, Mechanisms, and Treatment. Psychosom med 66 (2004): 305-315.

11. Pruett SB. Stress and the Immune System. Pathophysiology 9 (2003): 133-153.

12. Morey JN, Boggero IA, Scott AB, et al. Current Directions in Stress and Human Immune Function. Curropin Psychol 1 (2015): 13-17.

13. Segerstrom SC, Miller GE. Psychological stress and the human immune system: A meta-analytic study of 30 years of inquiry. psychological bulletin 130 (2004): 601-630.

14. Hussain D. Stress, Immunity, and Health: Research Findings and Implications. International Journal of Psychosocial Rehabilitation 15 (2010): 94-100.

15. House T, Keeling MJ. Household structure and infectious disease transmission Epidemiol. Infect 137 (2009): 654-661.

16. Marek Laskowski, Luiz C Mostaco-Guidolin, Amy L Greer, et al. The Impact of Demographic Variables on Disease Spread. Influenza in Remote Communities. Scientific Reports 1 (2011).

17. Denise L Doolan, Carlota Dobano, Kevin Baird J. Acquired Immunity to Malaria. Clin Microbiol Rev 2 (2009): 13-36.

18. World Health Organization (WHO). World Malaria Report. Geneva: World Health Organization (2009).

19. Leslie John F, Summerell Brett A, Suzanne Bullock. The Fusarium Laboratory Manual. Ames: Blackwell (2006): 250-254.

20. Summerell Brett A, Laurence Matthew H, Liew Edward CY, et al. Biogeography and phylogeography of Fusarium: A review. Fungal Diversity 44 (2010): 3-13.

21. Larone Davise H. Thermally Monomorphic Moulds. Medically Important Fungi: A Guide to Identification Washington, ASM Press (2011): 305.

22. Yamana TK, Eltahir EAB. Incorporating the Effects of Humidity in a Mechanistic Model of Anopheles Gambiae Mosquito Population Dynamics in the Sahel Region of Africa. parasit vectors 6 (2013): 235.

23. Fillinger U, Sonye G, Killeen GF, et al. The practical importance of permanent and semipermanent habitats for controlling aquatic stages of Anopheles gambiae sensu lato mosquitoes: Operational observations from a rural town in western Kenya. Trop Med Int Health 9 (2004): 1274-1289.

24. Gimnig JE, Ombok M, Kamau L, et al. Characteristics of larval anopheline (Diptera: Culicidae) habitats in Western Kenya. J Med Entomol 38 (2001): 282-288.

25. Tangerman A. Measurement and biological significance of the volatile sulfur compounds hydrogen sulfide, methanethiol and dimethyl sulfide in various biological matrices. Journal of Chromatography B 877 (2009): 3366-3377.

26. Gaoshuo Hu, Yongfu Xu, Long Jia. Effects of relative humidity on the characterization of a photochemical smog chamber. Journal of Environmental Sciences 23 (2018): 2013-2018. 
27. Salimifard P, Rim D, Gomes C, et al. Resuspension of biological particles from indoor surfaces: Effects of humidity and air swirl Sci. Total Environ 583 (2017): 241-247.

28. Otuu FC, Inya-Agha SI, Ani UG, et al. Air Pollution Tolerance Indices (APTI) of Six ornamental Plants Commonly Marketed at "Ebano Tunnel" Flora Market, in Enugu Urban, Enugu State Nigeria, IOSR. Journal of Environmental Science, Toxcicology and Food Technology 8 (2014): 51-55.

29. Enete IC, Chukwudeluzu VU, Okolie AO. Evaluation of Air Pollution Tolerance Index of Plants and Ornamental Shrubs in Enugu City: Implications for Urban Heat Island Effect, World Environment 3 (2013): 108-115.

30. Enete IC, Alabi MO, Chukwudelunzu VU. Tree Canopy Variation effects on urban heat Island in Enugu City, Nigerian. Developing Country Studies 2 (2012a): 12-18.

31. Armiya'u AY, Audu MD, Obembe A, et al. A study of psychiatry morbidity and co-morbid physical illness among convicted and awaiting trial inmates in Jos prison. Journal of Forensic and Legal Medicine 20 (2013): 1048-1051.

32. Onyemocho A, Ugande AA, Omale D, et al. Inmates perception of the living conditions in a medium security prison in north central nigeria. Highland medical research journal 17 (2017): 1.

33. Boone SA, Gerba CP. The Prevalence of Human Parainfluenza Virus I on Indoor Office Formite. Food and Environmental Virology 2 (2010): 41-46.

34. Faure O, Fricker-Hidalgo H, Lebeau B, et al. Eight years Surveillance of Environmental Fungal Contamination in Hospital Operating Rooms Haematological I units. Journal of Hospital Infections 50 (2002): 155-160.

35. Fatoye FO, Fatoye GK, Oyebanji AO, et al. Psychological characteristics as correlates of emotional burden in incarcerated offenders in Nigeria. East Afr Med J 83 (2006): 545-552

36. Huse T, Keeling M. Household structure and infectious disease transmission. Epidemiology and Infection 137 (2009): 654-661.

37. Kennedy DI, Enriquez CE, Gerba CP. Enteric Bacterial Contamination of Public Rest-rooms. Cleaning Industry Research Institute (2005).

38. Knope Katrina, Whelan Peter, Smith David, et al. Arboviral diseases and malaria in Australia, 2010-11: Annual report of the National Arbovirus and Malaria Advisory Committee. Communicable Diseases Intelligence Quarterly Report 37 (2013): 1-20.

39. Kibbler CC, MacKenzie DWR, Odds FC. Principles and practice of clinical mycology (Repr Edn.). Chichester: Wiley (1996): 13, 105.

40. Mazzali M, Jefferson JA, Ni Z, et al. Microvascular and Tubulointerstitial Injury Associated with Chronic Hypoxianduced Hypertension. Kidney Int 63 (2003): 2088-2093.

41. Martins N, Ferreira IC, Barros L, et al. Candidiasis: Predisposing factors, prevention, diagnosis and alternative treatment. Mycopathologia 177 (2014): 223-240.

42. Onyekachi J. Problems and Prospects of Administration of Nigerian Prison: Need for proper Rehabilitation of the Inmates in Nigeria Prisons. J Tourism Hospit 5 (2016): 228. 
43. Otter J, French G. Bacterial Contamination in touch Surfaces in the Public Transport System and in Public areas of a Hospital in London. Letters in Applied Microbiology 49 (2009): 803-805.

44. Reynolds KA. Hygiene of Environmental Surfaces. International Journal of Environmental Research 15 (2005): 225-234.

45. Richards MJ, Edwards JR, Culver DH, et al. Nosocomial Infections in Medical Intensive Care Units in the United States. National Nosocomial Infections Surveillance System. Crit Care Med 24 (1999): 887-892.

46. Rippon John Willard. Medical mycology: The pathogenic fungi and the pathogenic actinomycetes $\left(3^{\text {rd }}\right.$ Edn.). Philadelphia, PA: Saunders (1999).

47. Reynolds KA. Hygiene of environmental surfaces. International Journal of Environmental Health Research 15 (2005): 225-234

48. Sleigh DJ, Timbury MC. Notes on Medical Microbiology, (5 ${ }^{\text {th }}$ Edn.), Churchill Livingstone, New york (1998): 173 .

49. Ziebuhr W, Hennig S, Eckart M, et al. Nosocomial Infections by Staphylococcus Epidermidis: how a commensal bacterium turns into a pathogen. Int J Antimicrob Agents 28 (2006): 14-20.

Citation: Otuu Fred C, Shu Elvis N. Prevalent Diseases among Inmates in Three Federal Prisons in SouthEast Geopolitical Zone of Nigeria: A Peep into the Environmental Factors. Journal of Environmental Science and Public Health 3 (2019): 010-024.

(C) This article is an open access article distributed under the terms and conditions of the
Creative Commons Attribution (CC-BY) license 4.0

